\title{
Building Energy Modeling at District Scale through BIM Based Automatic Model Generation - Towards Building Envelope Optimization
}

\author{
Mathias Bouquerel ${ }^{1}$, Sébastien Bermes ${ }^{2}$, Adrien Brun ${ }^{3,4}$, Hassan Bouia ${ }^{1}$, Régis Lecussan ${ }^{2}$, \\ Benoît Charrier ${ }^{1}$ \\ ${ }^{1}$ EDF R\&D, Moret-Loing-et-Orvanne, France \\ ${ }^{2}$ EnerBIM, Seilh, France \\ ${ }^{3}$ Univ. Grenoble Alpes, Grenoble, France \\ ${ }^{4}$ CEA, LITEN/DTS/SBST, Grenoble, France
}

\begin{abstract}
When a new construction is added in a dense area, the existing district may have a significant influence on the new building energy performance, and vice-versa. These interactions are almost never taken into account in the modeling tools used for building design. This paper presents a numerical platform, design within the ANR MERUBBI project, able to assess building energy performance at the district scale, taking into account the mutual interactions of the buildings located in the same urban island. This platform is intended to promote efficient building design through an optimization process applied to the configuration of the building envelope.
\end{abstract}

\section{Introduction}

Buildings are responsible for a large part of energy consumption and greenhouse gas emissions. Improving their energy efficiency is therefore a crucial issue for the reduction of global energy demand and limitation of global warming. In addition, the construction sector is currently undergoing two major transformations, which could assist in reaching these outlined goals.

First, digitalization is ongoing in the construction sector through the development of the BIM (Astman et al., 2008) - Building Information Model - a numerical description of the 3D geometry and properties of a building. The BIM supports collaborative and interdisciplinary buildings design, construction, and operation.

Second, the increase in urban densification leads to an increase of interactions between buildings, especially in dense areas. While buildings were, until recently, designed without considering the surrounding buildings, it is now mandatory to include the interactions between buildings in dense areas in order to guarantee the high energy efficiency asked for new or renovated buildings.

In this context, the ANR MERUBBI project (Schumann et al., 2017) was carried out from 2014 to 2018 by several partners with the aim of developing a new methodology for building design. This methodology is supposed to maximize the use of the freely available energy resources of the building's environment (Sun irradiation for space heating, air or ground temperature for space cooling...). This methodology is inspired by the bioclimatic indicators (Chesné et al., 2012), which measure how a building is able to use free energy potentials. So accurate assessment of the potential for each free energy resource is required.
The MERUBBI platform, presented in this paper, has been developed for the calculation of several key performance indicators (KPIs) regarding the bioclimatic, energy, and economic performances of any building design, taking into account the mutual interactions between the buildings in an existing district and the new building(s) to be integrated in. For this purpose, this platform runs Building Energy Modeling (BEM) at the district scale thanks to a specific BIM-based automatic model generation tool. The final purpose of this platform is, through an optimization process, to support the architects and urban planners by selecting building designs with high performances regarding selected KPIs.

\section{The MERUBBI platform}

\section{General considerations}

Considering the goal of this platform, the following functionalities are expected:

- Importation of the district geometry

- Assignment of building envelope properties

- Assignment of building use

- Assessment of energy and bioclimatic KPIs

- Assessment of the total cost

- Multi-criteria optimization

The MERUBBI platform is based on modular architecture, in order to allow a simultaneous step-by-step development of the different modules. The communication between the modules is done through file exchange, with open standards for data files (allowing as much communication as possible).

Figure 1 presents the general architecture of the plaform, which can be split into two sub-units: the problem definition and the problem resolution. The purple blocks are the software bricks developed for the platform, orange blocks are the exchange files, yellow blocks detail the content of exchange files or software bricks, and the grey blocks are functionnalities that were expected but not developed due to a lack of resources.

\section{Pre-processing tool}

The pre-processing tool needs to manage data in the form of a thermal mockup. Such a thermal mockup either comes from gbXML files (Green Building XML, 2017), or from IDF EnergyPlus ${ }^{\mathrm{TM}}$ files (US Department of Energy, 2018). Our pre-processing tool also allows for the insertion of buildings in an existing district from various files. 


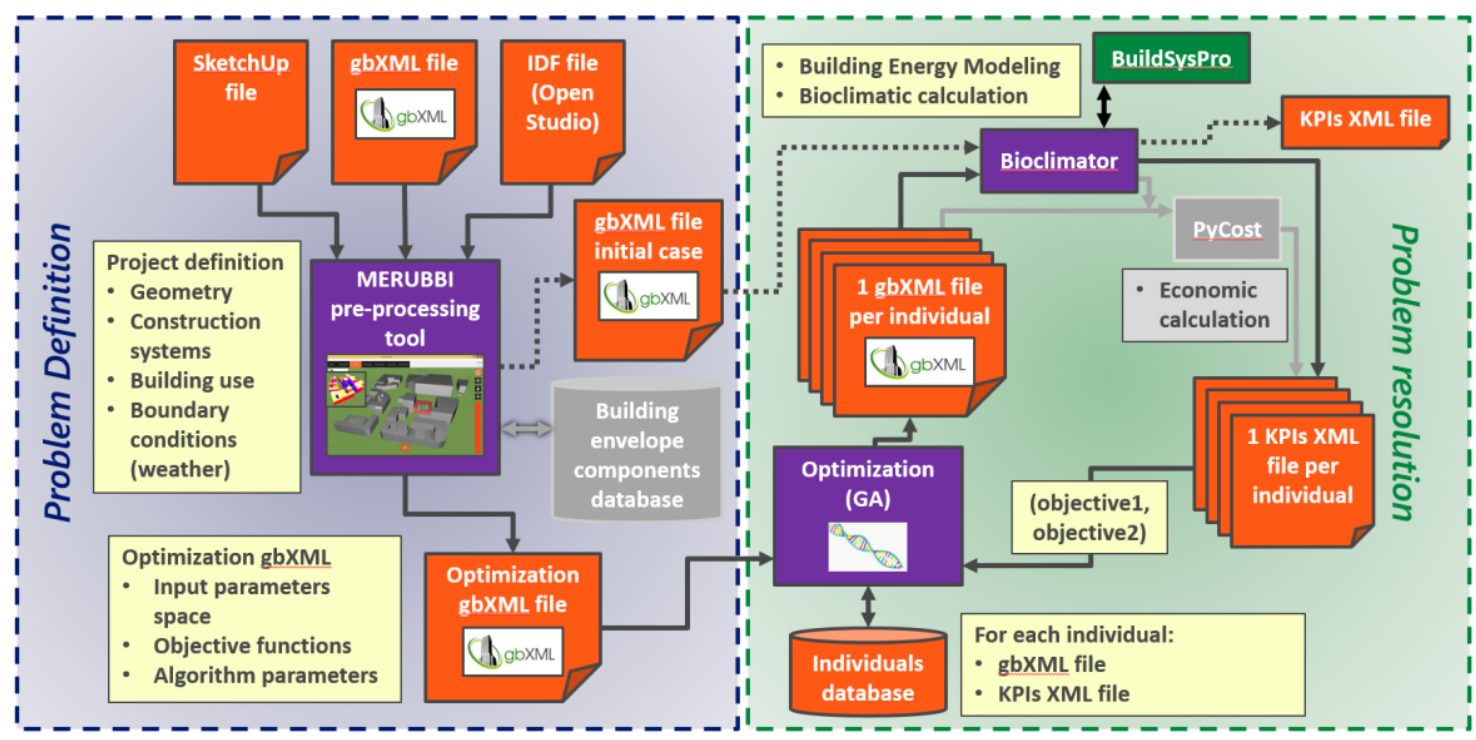

Figure 1: MERUBBI platform architecture

The pre-processing tool provides a geometrical and analysis tool that can convert a simple SketchUp ${ }^{\mathrm{TM}}$ file into a thermal mockup. This tool can detect building spaces with a ray tracing 3D filling algorithm, and then extracts interfaces between spaces, which will be semantized as walls, floors, roofs or openings, as well as the location of the linear thermal bridges.

Once the geometry is imported, the pre-processing tool provides a set of tools to edit the components of building, with the only limitation being the lack of change to the geometry. These are used to set all the data needed for solar and thermal calculation:

- Hierarchy of District / Buildings / Zones / Spaces;

- Boundary conditions: possibility to set a specific boundary condition (soil, crawlspace, adiabatic, heated or non-heated room) for each surface;

- Usages: possibility to define and schedule heating / cooling / lighting / ventilation / internal gains scenarios;

- Construction systems: possibility to define materials, constructions and apply them to various walls / floors / roofs. Possibility to set thermal characteristics of openings;

- Thermal bridges: possibility to set thermal bridge coefficients individually or by type;

Solar calculation on the building envelope is carried out as a pre-process to thermal calculation. For this purpose, the software can localize the project with a weather data file (TMY2 or EnergyPlus ${ }^{\mathrm{TM}}$ EPW).

We use a Monte-Carlo ray tracing approach to calculate solar irradiance on each element of the envelope (walls, roofs, openings). For performance matters, we compute several independent layers: diffuse irradiance on one layer, direct irradiance from various key positions of the sun throughout the year on other layers. We focus on a subset of approximately 144 key positions of the sun: 1 day per month and one position per hour when the Sun is visible. The other days are interpolated before applying weather data. In the end, we compute hourly solar irradiance for each element, and we can distinguish between direct-direct, direct-reflected, diffuse-direct, diffuse-reflected components (see figure 2).
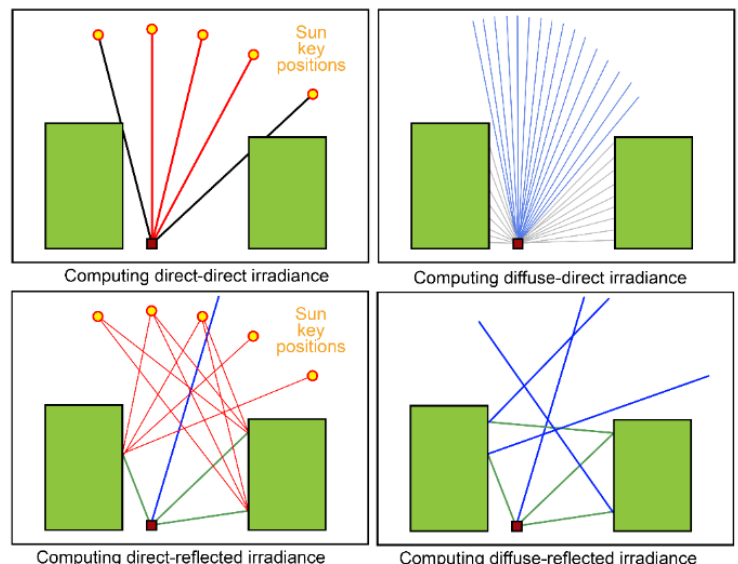

Figure 2: Monte-Carlo ray tracing

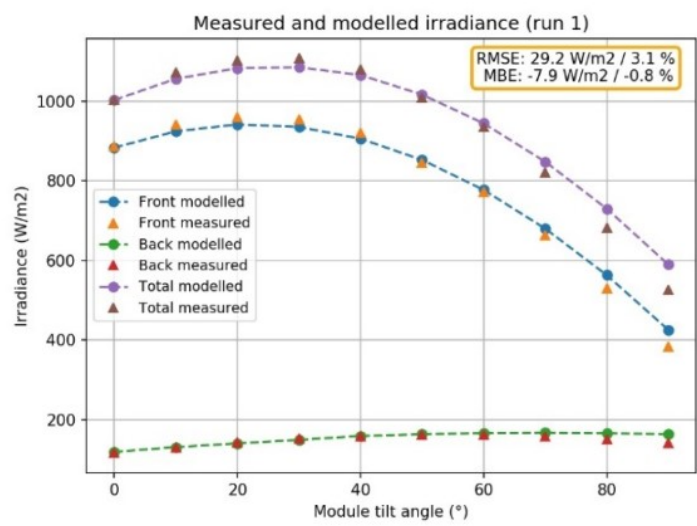

Figure 3: Comparison between irradiance from measurements and from Monte Carlo ray tracing calculation (Chiodetti et al, 2018)

This Monte-Carlo ray tracing computation tool has been also used for PV calculation (Lindsay et al, 2018; Chiodetti et al, 2018). It has been validated in this context through comparison with experimental data (see for example Figure 3). 
Solar irradiance data can be displayed in the preprocessing tool and exported as CSV files with various time scales (hourly, daily, monthly and annual irradiation, see figure 3 ). We also provide a tool that can compare solar irradiance on a district with or without a given building. To do so, the pre-processing tool run two solar calculations, one without and one with the building. We can then precisely measure the impact of the new building on each component of the district, from a whole building to a single window.

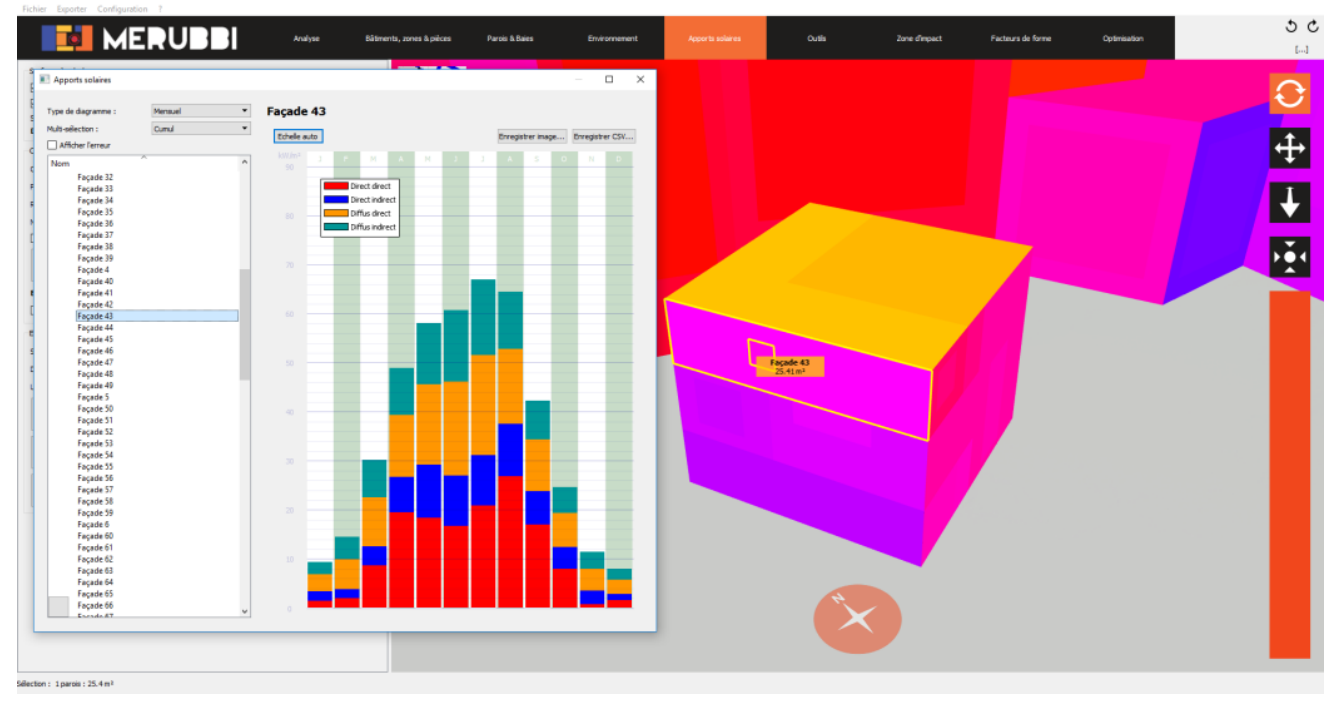

Figure 4: Solar calculation on a facade

\section{Bioclimator}

The Bioclimator - bioclimatic indicator calculator - is a python package dedicated to Building Energy Modeling (BEM) and bioclimatic calculation at the district scale. Three steps are needed to perform this task: model generation, model simulation, and post-processing.

First, a translation function called PyRosette converts the building thermal description stored in the gbXML file into a building energy model. This model is based on BuildSysPro, an open source Modelica library developed by EDF R\&D which contains elementary models for building energy modeling. The Figure 5 gives an example of a single building energy model built with BuildSysPro. This model contains the building envelope (façade walls, roof, floor, windows), the internal air volume (blue disk), a ventilation model, and a weather simulator (left part). It can be used to simulate the free evolution temperature of a simple building.

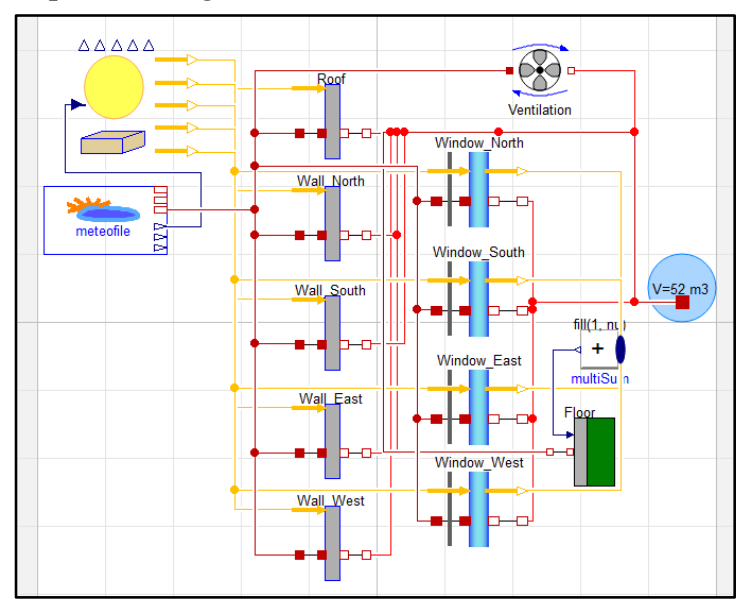

Figure 5: Example of a single building energy model based on BuildSysPro
BuildSysPro has been validated through numerical comparisons with the IEA BESTEST procedure (Plessis et al., 2014), which is illustrated on Figure 6 and through comparison with experimental results (Bontemps et al., 2013), which is illustrated on Figure 7.

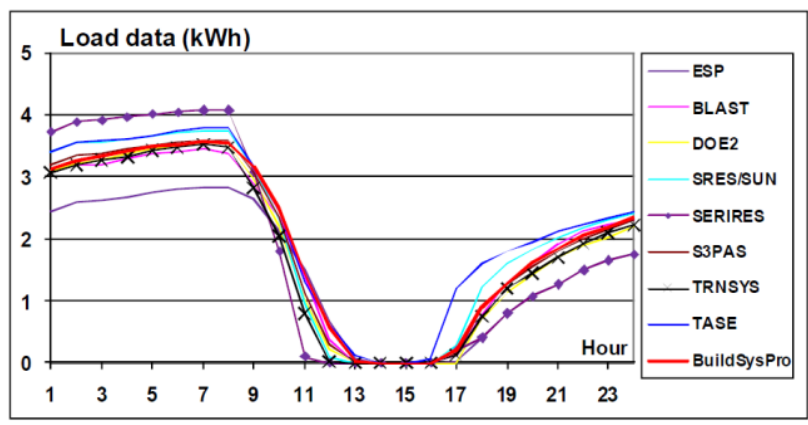

Figure 6: numerical comparison from IEA BESTEST procedure (Plessis et al., 2014)

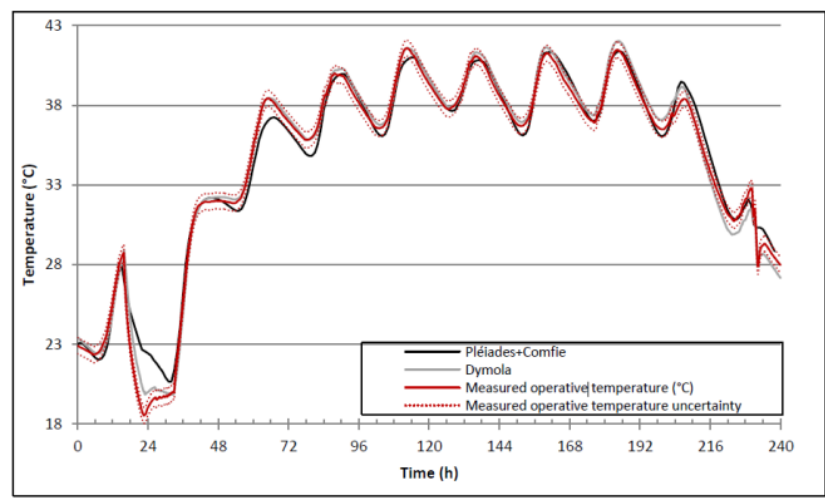

Figure 7: comparison between experimental results (red) and numerical results from BuildSysPro (grey) and another simulation tool (line) (Bontemps et al., 2013) 
The gbXML schema and BuildSysPro models are both based on an object-oriented description of a building, with a very similar level of segmentation and details. Thus, the translation from gbXML to Modelica is fairly natural: for each gbXML tag, a corresponding Modelica model can be found in BuildSysPro. So the process is done through the following actions:

1. to parse the gbXML in order to get the list of building components to be integrated in the BEM

2. to instantiate in a Modelica template each building component as a BuildSysPro model instance

3. to set the parameters of each instance according to the attributes of the corresponding gbXML tag

4. to connect in the Modelica model all instances according to their relations stated in the gbXML through the ID references system.

The second step is to simulate the Modelica model, which is done thanks to the commercial software Dymola, with the adaptive time step solver CVODE. The model is run over one full year, and the simulation results exported with an hourly time step resolution.

The final step is to post-process the simulation results in order to produce the energy and bioclimatic KPIs: energy demand for heating and cooling, solar covering rate, and exploitation rate of the Sun (Chesné et al, 2012). These KPIs are stored in a XML file where the buildings and rooms are identified according to the original gbXML IDs.

The Bioclimator can be run only for one single configuration, namely a completely defined existing district and new building design. Therefore, it is possible to run it on the initial case (dotted line on Figure 1) or on each individual generated by the optimization algorithm (that is a defined configuration) to be evaluated (solid line on Figure 1). It is however not possible to run it on the Optimization gbXML file exported from the preprocessing tool since this file contains the input parameters space but not a well-defined configuration.

\section{Optimization (Genetic Algorithm)}

An optimization module has been integrated in the MERUBBI platform. It aims to help the user design an effective solution in a minimum amount of time and investment. There are a large number of optimization methods. Here are the specifications that allowed us to choose the most appropriate algorithm:

- multi-criteria: there can be more than one goal, for example to maximize solar resource and minimize energy needs for cooling. In our context, it is important that the algorithm suggest a set of nearoptimal solutions. This way, the optimization process does not impose a solution but exhibits a group of interesting solution. The final arbitration is done by the decision maker;

- derivative-free : we do not know the partial derivatives of the objective functions;

- the design parameters can vary continuously over an interval or take discrete values;
- the implementation of the algorithm must be flexible enough to allow rapid development;

- It must allow the use of distributed computing to speed-up the process;

According to the previous criteria, we chose a genetic algorithm that meets all of our demands (native multicriteria method, derivative-free, distributed computing). Indeed, this algorithm is very widely used in building and HVAC design (Machairas et al., 2014; Nguyen et al., 2014; Chantrelle et al., 2011) and the most used algorithm in bioclimatic design (Stevanovic, 2013). More specifically, we opted for the NSGAII (Non-dominated Sorting Genetic Algorithm-II) algorithm which is a revised version of the former NSGA (Srinivas, 1994) elaborated following a suggestion from Goldberg (1989). Our implementation of the algorithm is based on the python DEAP framework (Fortin, 2012), being developed since 2009 at Laval University, Canada. This package provides all the objects necessary for a rapid prototyping. The right frame of the Figure 1 shows how the optimization process has been integrated in the MERUBBI platform.

The definition of the optimization problem is done under the MERUBBI pre-processing tool. The user can select the elements to be optimized:

- Opaque wall composition: either fully (by providing a list of opaque wall compositions for full substitution), either locally (by providing for example a set of values for the insulation layer thickness or a set of materials for a given layer).

- Thermal characteristics of openings: the user can provide a list of opening types for substitution of a given type. Thus, openings can be optimized separately on various orientations.

The optimization script gets the Optimization gbXML file as input. For each generation, a set of individuals (in the form of gbXML files) are generated and assessed thanks to the Bioclimator module. The KPIs of each individual are used in order to generate the next generation. Parameters and KPIs of the population are stored so that no individual is assessed twice.

The algorithm outputs are XML files containing the individual parameters and KPIs, and a synthesis for each generation as a CSV file. The synthesis lists the assessed individuals and those being on the Pareto frontier.

For the moment, the changes that can be made to the case study in the optimization process are limited to the building envelope material properties and glazing properties, except for the short wave radiative properties. Indeed, they can be changed, but since the solar calculation is done only once as a pre-processing step, the solar irradiation is not updated according to the new short wave surface properties so the calculation is not fully taking into account a change of short wave radiative properties. 


\section{Results}

The ANR MERUBBI project brings together several actors of building construction and urban design to develop a building design platform at district scale (Schumann et al., 2017). To be as realistic as possible, architect student from the school of architecture of Strasbourg (ENSAS) and Versailles (ENSAV) designed three variations of three case studies (in Strasbourg, Paris and Nantes), for an increasingly constrained context (isolated building, moderately dense and high-density district). The two case studies out of nine presented here are from this work.

\section{Strasbourg case study (high density)}

In the first case study we consider the implantation of a new office building in a dense residential district of Strasbourg, France (Ribault et al, 2017). An empty square located in an existing district (Figure 8.a) is used for this implantation. The 3D model for the existing district of Strasbourg made on SketchUp ${ }^{\mathrm{TM}}$ includes 22 buildings. In this model, slopped roofs have been replaced by flat roofs.

The new office building is a nine-storey tower, with a glazed façade in all orientations and solar protections on all storeys except the ground floor. The heated area is $1560 \mathrm{~m}^{2}$. The artist's rendition in shown in Figure 8.b.

(a)
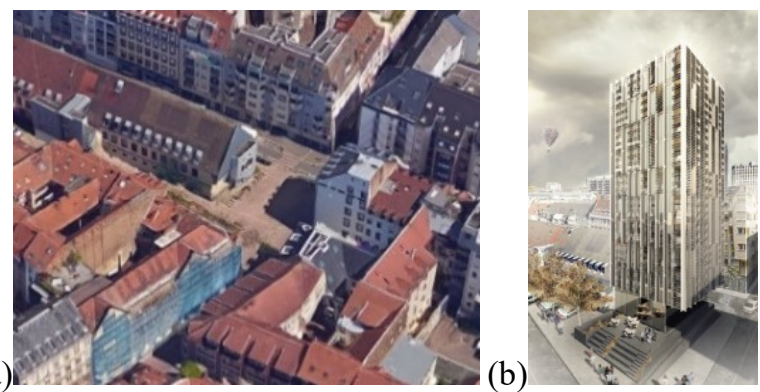

Figure 8: (a) Existing district of Strasbourg: Google view - (b) New office building project: artist's rendition

One goal of this case study is to measure how the energy needs assessment is impacted by taking into account the interaction between the new project and the existing district. This evaluation was conducted for both the new building project and the existing district buildings. So three models are considered:

- ED: Existing District alone

- P: Project of new building alone

- PinED: full model of the new building Project in the Existing District

The 3D view of these models, generated from SketchUp ${ }^{\mathrm{TM}}$ files, are in Figure 9 where the surface colors are set according to the annual solar irradiation. The detailed configuration (construction system, usage scenarios) are available in Ribault et al. 2017.

The interactions between the existing district and the new building project included in the model are the solar shading and solar reflection on all building surfaces. Their impact on the energy needs can be assessed by comparing the $\mathrm{P}$ and PinED simulation results on one hand (Figure 10), and the ED and PinED simulation results on the other hand (Figure 11). (a)
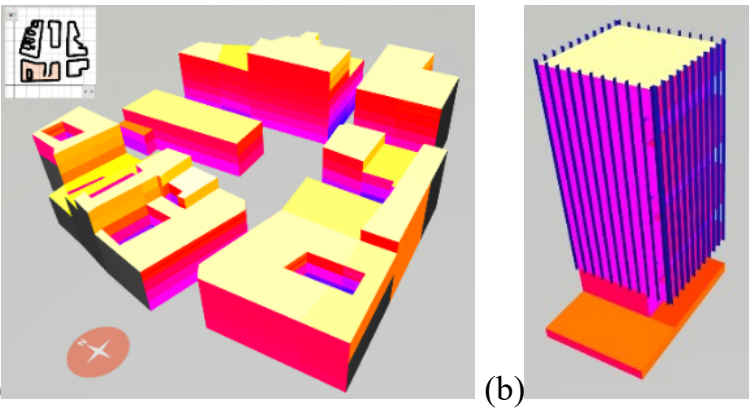

(b)

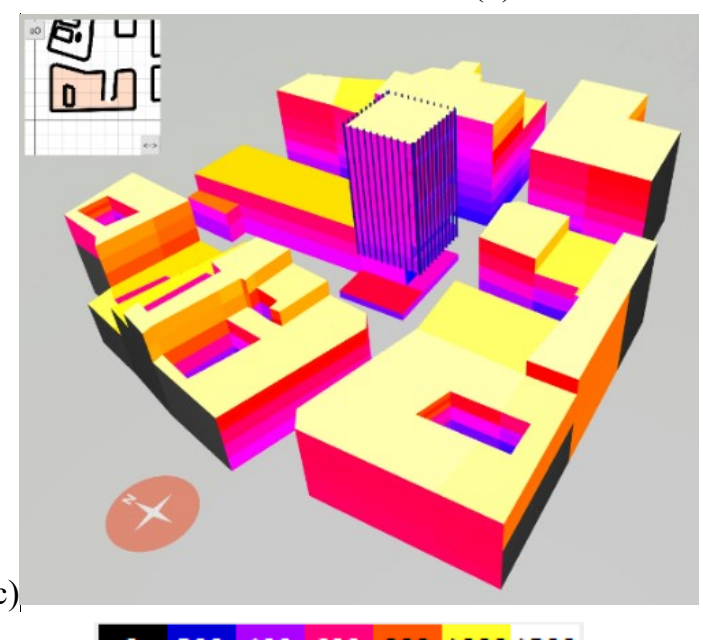

$\begin{array}{llllll}0 & 200 & 400 & 600 & 800 & 10001200\end{array}$

Figure 9: $3 D$ views of respectively $E D(a), P(b)$, and PinED (c) cases in MERUBBI pre-processing tool $\left(\right.$ surface colour $=$ annual solar irradiation $\left.\left[\mathrm{kWh} / \mathrm{m}^{2}\right]\right)$
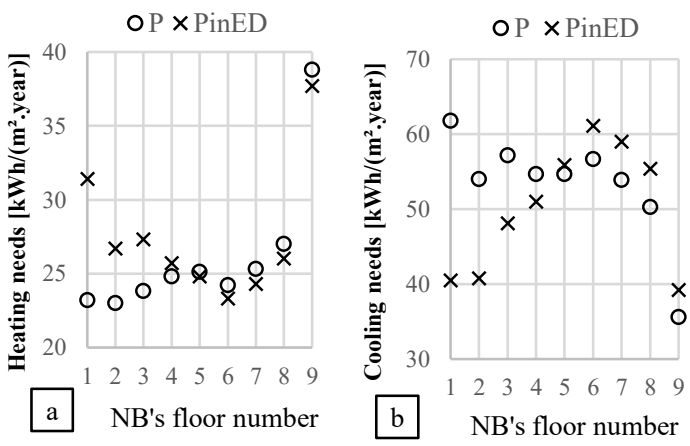

Figure 10: Impact of the existing district on the new building project energy needs

At the building scale, the existing district is responsible for a $5 \%$ increase in heating needs and $6 \%$ decrease in cooling needs of the new building. Therefore, for this case study, shading effect exceeds reflection effects at the building scale, since the differences in heating and cooling needs are only due to the decrease of solar gains when comparing $\mathrm{P}$ with PinED. When looking floor by floor, the impact depends on the floor position: for the bottom part (floors 1 to 4 ) heating needs increase and cooling needs decrease, whereas the opposite is observed for the top part (floors 5 to 9), however with a lower relative variation. This is a predictable effect: solar shading effect is more important for a low altitude. The first floor is indeed the most impacted, with 35\% more heating needs and $35 \%$ less cooling needs, while variations are not higher than $10 \%$ for all other floors. 

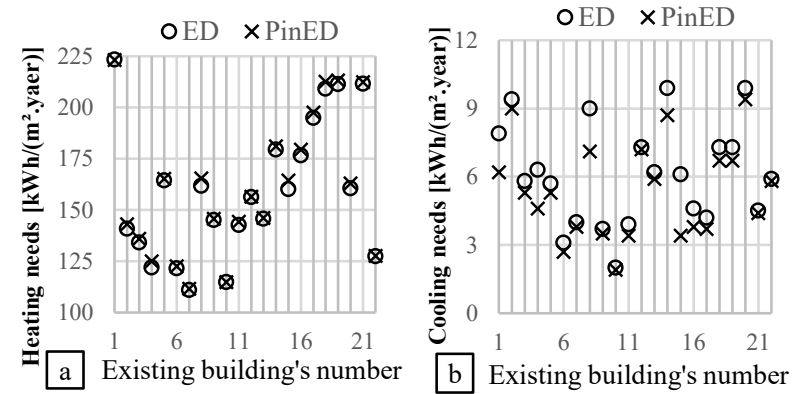

Figure 11: Impact of the new building project on the existing district energy needs

The relative impact of the new building on the existing district heating needs is fairly low: between $-0.1 \%$ and $+2.3 \%$, depending on the building, with a weighted average of $+1.0 \%$. The relative impact is higher for the cooling needs: $-1 \%$ to $-44 \%$, with a weighted average of $-13.1 \%$, but the absolute difference is still low: less than $1 \mathrm{kWh} /\left(\mathrm{m}^{2} . \mathrm{y}\right)$ for most buildings, and between 1 and 3 $\mathrm{kWh} /\left(\mathrm{m}^{2} . \mathrm{y}\right)$ for only 5 buildings out of 22 . It is moreover likely that these residential buildings are not equipped with a cooling system, considering the very low cooling needs, so the impact on the cooling needs could be considered equal to 0 .

Table 1 : Total heating and cooling needs for existing district (ED) and new building project

\begin{tabular}{|c|c|c|}
\hline & $\begin{array}{c}\text { Heating } \\
\text { needs } \\
{[\mathrm{MWh} / \mathrm{y}]}\end{array}$ & $\begin{array}{c}\text { Cooling } \\
\text { needs } \\
{[\mathrm{MWh} / \mathrm{y}]}\end{array}$ \\
\hline $\begin{array}{c}\text { Total for ED without impact of } \\
\text { the new building (in ED) }\end{array}$ & 3031.0 & 121.1 \\
\hline $\begin{array}{c}\text { Total for ED with impact of the } \\
\text { new building (in PinED) }\end{array}$ & 3062.4 & 105.2 \\
\hline Impact of new building on ED & 31.4 & $-\mathbf{- 1 5 . 9}$ (or 0) \\
\hline New building (in PinED) & $\mathbf{4 3 . 0}$ & $\mathbf{7 8 . 3}$ \\
\hline $\begin{array}{c}\text { Total increase of energy needs } \\
\text { due to the new building }\end{array}$ & $\begin{array}{c}\text { 152.7 } \\
\text { (if ED cooling needs } \\
\text { are neglected) }\end{array}$ \\
\hline
\end{tabular}

However the increase of heating needs for the 22 buildings considered in the existing district model is up to 31.4 MWh/y (see Table 1), which is in the same order of magnitude as the heating and cooling needs for the new building (PinED model): respectively 43.0 MWh/y and $78.3 \mathrm{MWh} / \mathrm{y}$. Indeed, $+1 \%$ is a low increase, but applied to 22 buildings (heated area $=22600 \mathrm{~m}^{2}$ ) with a fairly bad energy efficiency (heating need around $150 \mathrm{kWh} / \mathrm{m}^{2}$.y on average), the result is a significant increase of the energy needs for the district. In other words, when considering the additional energy needs in the district due to the new building, the impact of existing district heating needs increase by roughly $20 \%$ of the total energy needs increase if the cooling needs of existing district buildings are not considered (31.4 MWh/y on the $152.7 \mathrm{MWh} / \mathrm{y})$. Therefore, neglecting this effect leads to the underestimation of the total energy needs increase.

\section{Paris case study (moderately dense)}

The objective here is to increase the density of a moderately dense residential neighborhood located in Trappes (France). It is about building a house surrounded by high-rise residential buildings therefore taking the urban environment into account is essential. The main architectural concept of this project is to organize the rooms around a central core in double height largely glazed on its south facade. The glazed roof of the kitchen gives a luminous atrium.

The new building is surrounded by 25 buildings, 7 of which are represented by a one or two thermal zone and 19 other are considered in the CLO radiative pretreatment step only. A 10 thermal zone modeling is carried out for the new building while considering simplified occupancy scenario. We set constant heating and cooling set point, respectively $20^{\circ} \mathrm{C}$ and $26^{\circ} \mathrm{C}$, constant $0.75 \mathrm{ACH}$ and $5 \mathrm{~W} / \mathrm{m}^{2}$ thermal load.

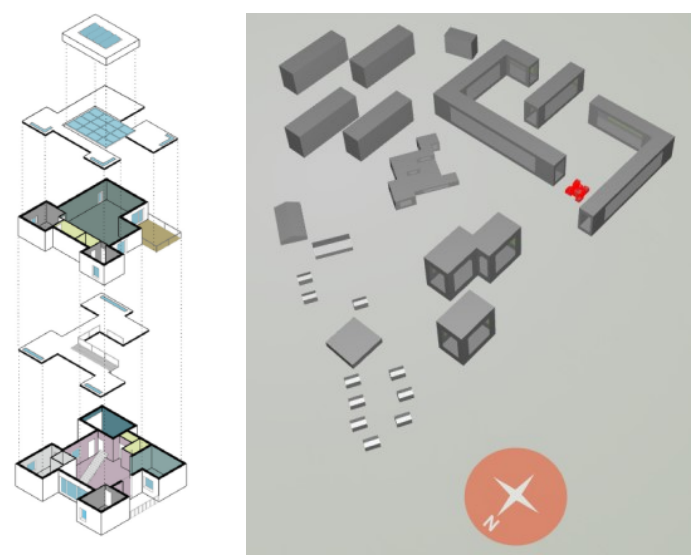

Figure 12: (Left) Exploded axonometric view of the project, (Right)-Project (red building) in its environment

We use the optimization algorithm to help in the choice of constructive features of the project. Table 2 presents the parameters of the model that can be modified by the algorithm. The parameters space is composed of discrete values only forming 7500 possible combinations. Table 3, Table 4 and Table 5 present the description of the wall compositions and windows used.

Table 2: Optimization parameters

\begin{tabular}{|c|c|}
\hline name & Possible composition \\
\hline South W. & DG65; DG53; DG38; DG33;TG54 \\
\hline North W. & DG65; DG53; DG38; DG33;TG54 \\
\hline East W. & DG65; DG53; DG38; DG33;TG54 \\
\hline Roof W. & DG65; DG53; DG38; DG33;TG54 \\
\hline Façade Wall & WoodFrameR10; ConcreteR5; BrickR4; SiporexR3 \\
\hline Partition & ConcreteW275; BrickW96; BA13W26 \\
\hline
\end{tabular}

Table 3: Windows properties

\begin{tabular}{|c|c|c|c|c|}
\hline name & & $\begin{array}{c}\mathbf{U} \\
\left(\mathbf{W} /\left(\mathbf{m}^{\mathbf{2}} \mathbf{. K}\right) \mathbf{)}\right.\end{array}$ & $\begin{array}{c}\text { Ts } \\
\mathbf{( \% )}\end{array}$ & $\begin{array}{c}\text { Tl } \\
(\mathbf{\%})\end{array}$ \\
\hline planitherm_xn & DG65 & 1.1 & 65 & 82 \\
\hline planitherm_one & DG53 & 1 & 53 & 73 \\
\hline planistar_sun & DG38 & 1 & 38 & 72 \\
\hline planiclear_coollite & DG33 & 1 & 33 & 55 \\
\hline planitherm_xn & TG54 & 0.6 & 54 & 74 \\
\hline
\end{tabular}


Table 4: Façade wall construction

\begin{tabular}{|c|c|c|}
\hline name & Composition (ext $->$ int) & $\begin{array}{c}\mathbf{R} \\
\left(\mathbf{m}^{\mathbf{2}} \mathbf{. K} / \mathbf{W}\right)\end{array}$ \\
\hline $\begin{array}{c}\text { Woodframe } \\
\text { R10 }\end{array}$ & $\begin{array}{c}\text { PSE30->CTBH25-> } \\
\text { Steicoflex380-> } \\
\text { CTBH16->BA13 }\end{array}$ & 10.7 \\
\hline ConcreteR5 & PSE160->Concrete200 & 5.28 \\
\hline BrickR4 & PSE80-Gelis375 & 4.87 \\
\hline SiporexR3 & Siporex370 & 2.94 \\
\hline
\end{tabular}

Table 5: Partition construction

\begin{tabular}{|c|c|c|}
\hline name & Composition (ext -> int) & $\mathbf{~ k g / \mathbf { m } ^ { 2 }}$ \\
\hline ConcreteW275 & $\begin{array}{c}\text { Eternit12->Concrete100- } \\
\text { >Eternit12 }\end{array}$ & 275 \\
\hline BrickW96 & Plaster20 ->Brick50->Plaster20 & 96 \\
\hline BA13W26 & BA13->AirGap40->BA13 & 26 \\
\hline
\end{tabular}

The optimization was carried out with the following parameters: minimization of the annual heating and cooling needs of the construction project, population of 28 individuals per generation and evolution over 40 generations.

The results are presented in Figure 13. Each subfigures presents the value of one of the six optimization parameters by the color of the marker. In order to improve the readability, only the quasi-optimal solutions are detailed. The other are displayed as small dotted marker in background.

This representation shows that:

- Only wood frame and concrete façade wall construction are represented on the Pareto frontier

- With regard to glazing, lowest U-value and solar transmission are preferred so the planitherm_xn and planitherm_one are not represented

- Light internal partitions are mostly used. Indeed, there is no summer nocturnal natural ventilation which allow to highlight the interest of thermal inertia

- Lowest solar transmission windows are retained for the roof windows

\section{Conclusion and Outlook}

We have presented a simulation platform that can:

- Analyze a district geometry description and convert it into a building thermal description at the district scale

- Edit all characteristics of the district thermal description

- Compute detailed solar irradiance calculation over the district for each building surface while taking into account the solar masking and reflections due to all other surfaces

- Perform building energy calculations in order to assess the energy performances (heating and cooling needs) and bioclimatic performances (solar coverage rate and exploitation rate) for each building
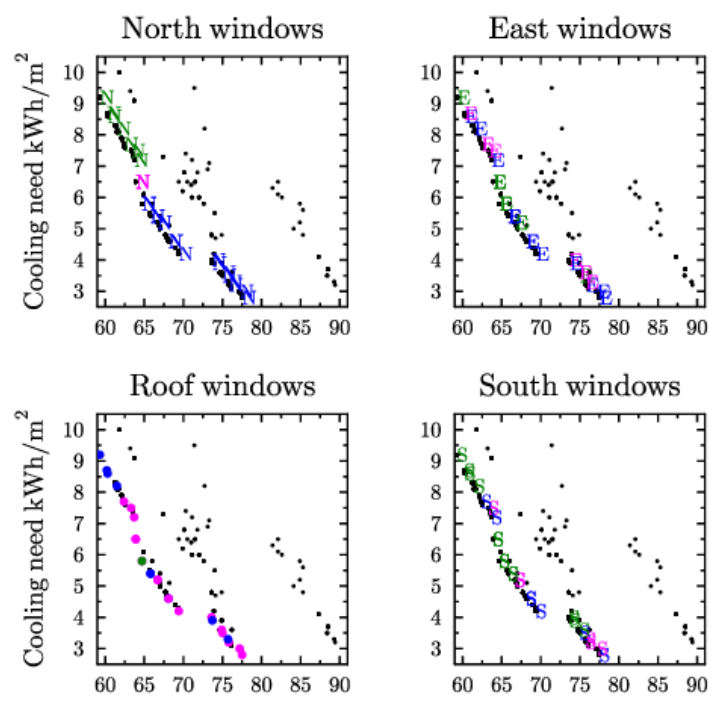

South windows
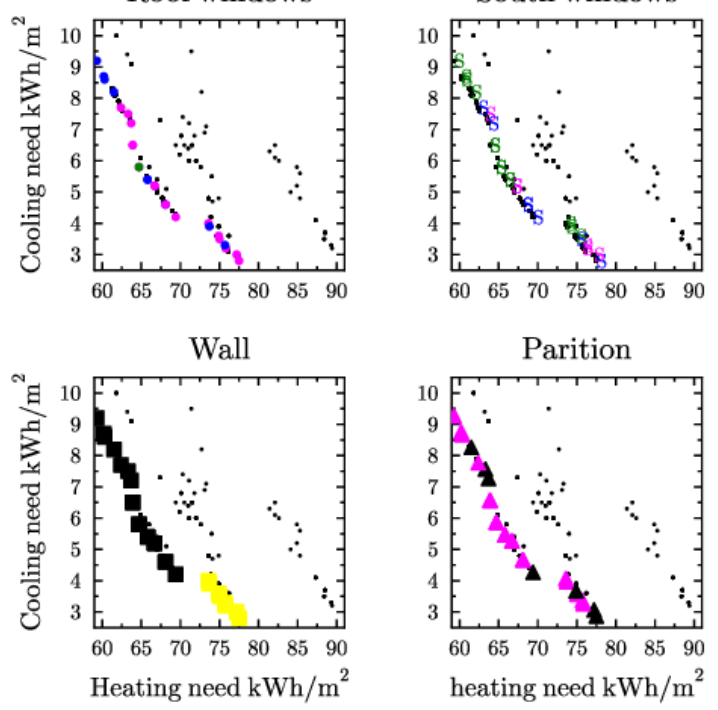

Figure 13: Optimization results

- Apply an optimization process to the building's component properties in order to assist in the design of high performance buildings

Most of these functionalities are available through graphical interfaces or simple python functions, requiring minor manual operations. The final design of the platform is not as user-friendly as commercial software could be, but it is a decent tool that can be used to conduct a complete study with a limited required time.

We have conducted a first validation step by comparing the results of our platform with EnergyPlus ${ }^{\mathrm{TM}}$ and Pleiade $^{\mathrm{TM}}$ simulation tools (Ribault et al, 2017). To date, there is no experimental validation database at the neighborhood level. It would be interesting to build and make available to the community one or more documented real case studies.

The issue remains on the input data: a tool is needed to produce the geometry to be imported, and some rules shall be applied when creating these geometry files so that the import do not fail. Future developments include the ability to connect directly to Urban/BIM model standards, especially for getting rid of these geometry file issues. Urban model standards (for example CityGml) provide a lot of information to automatize district data import. BIM models (such as IFC) could then be used for some specific buildings to provide more detailed information. 
Regarding optimization, several developments were discussed:

- A method for generating a reduced weather sequence has been proposed and tested on a simple case in order to limit the simulation time. This method needs to be experienced on a multi-building case study.

- Taking into account the constructive constraints will reduce the size of the parameter space. Introducing these considerations will speed up the convergence of the algorithm.

- The ability of evolutionary algorithms to be parallelized could be exploited, by using a dedicated python toolbox like SCOOP for instance. Make the most of multi-core architecture is one more way to speed up optimization.

- It would be interesting to optimize properties or object like overhang, wall reflective properties, position and size of the windows. To this end, the optimization workflow must update and integrate solar radiation calculation for the calculation of each individual KPIs.

We have also begun to work on long wave radiative exchanges between the buildings of the district. Building surfaces may exchange long wave radiative fluxes inside the district as soon as they have different surface temperatures. The pre-processing tool is able to compute the form factors between all walls and openings of all buildings. This exchange matrix can then be used in a closed loop during thermal calculation. In the process we had to face prohibitive calculation durations. We hope to cut down complexity by reducing the exchange matrix, through filtering the form factor matrices, or by focusing on shorter time range.

\section{Acknowledgments}

This project has received support from the French State Program "Investment for the Future" bearing the reference (ANR-10-ITE-0003).

\section{References}

Astman, C. \& al. (2008). BIM Handbook: A Guide to Building Information Modeling for Owners, Managers, Designers, Engineers, and Contractors. John Wiley \& Sons, Inc. (USA).

Bontemps, S., Kaemmerlen; A., Blatman, G., Mora, L. (2013). Reliability of dynamic simulation models for building energy in the context of low-energy buildings. Proceedings of Building Simulation 2013. Chambéry (France), 25-28 August 2013.Chantrelle, F.P., Lahmidi, H., Keilholz, W., El Mankibi, M., Michel, P. (2011). Development of a multicriteria tool for optimizing the renovation of buildings. Applied Energy(Volume 88), 1386-1394.

Chesné, L., Duforestel, T., Roux, J-J., Rusaouën, G. (2012). Energy saving and environmental resources potentials: Toward new methods of building design. Building and Environment(Volume 58), 199-207.
Chiodetti, M., Kang, J., Reise, C., Lindsay. (2018) Predicting Yields of Bifacial PV Power Plants - What Accuracy Is Possible?. Proceedings of the EU PVSEC 2018. Brussels (Belgium), 24-28 September 2018

Fortin, F-A., De Rainville, F-M., Gardner, M-A. Parizeau, Gagné., C. (2012). DEAP: Evolutionary Algorithms Made Easy. Journal of Machine Learning Research (Issue 13), 2171-2175.

Green Building XML (2017). gbXML Schema 6.01.

Goldberg, D.E. (1989). Genetic algorithms in search, optimization, and machine learning. Addison-Wesley. Boston (USA).

Lindsay, A., Chiodetti., Binesti, D., Mousel, S., Lutun, E., Radouane, K., Bermes, S., Lecussan, R. (2016). Enhancing bifacial PV modelling with ray-tracing. Proceedings of the 6th PV PMC Workshop. Freiburg im Breisgau (Germany), 24-26 October 2016.

Machairas, V., Tsangrassoulis, A., Axarli, K. (2014). Algorithms for optimization of building design: A review. Sustainable Energy Reviews(Volume 31), 101-112.

Nguyen, A.-T., Reiter, S., Rigo, P. (2014). A review on simulation-based optimization methods applied to building performance analysis. Applied Energy(Volume 113), 1043-1058.

Plessis G., Kaemmerlen A., Lindsay A. (2014). BuildSysPro: a Modelica library for modelling buildings and energy systems. Proceedings of the $10^{\text {th }}$ International Modelica Conference. Lund (Sweden) 10-12 March 2014.

Ribault, C., Bouquerel, M., Brun, A., Schumann, M. Rusaouen, G., Wurtz, E. (2017). Assessing tools relevance for energy simulation at the urban scale: towards decision-support tools for urban design and densification. Proceedings of CISBAT. Lausanne (Switzerland), 6-8 September 2017.

Ribault, C., Méthode d'optimisation multicritère pour l'aide à la conception des projets de densification urbaine, thesis. INSA Lyon, 2017, 215 p.

Schumann, M., Duforestel, T., Bouia, H., Bouquerel, M., Brun, A., Ribault, C., Leduc, T., Hoyet, N., De Fouquet, M., Dufrasnes, E., Sonnet, J-M., Lécussan, R., Rusaouen, G (2017). Interdisciplinarity around design tools for new buildings and districts: the ANR MERUBBI project. Proceedings of PLEA 2017. Edinburgh (Scotland), 3-5 July 2017.

Srinivas, S., Kalyanmoy Deb (1994). Multiobjective optimization using nondominated sorting in genetic algorithms. Evolutionary Computation (Volume 2 Issue 3), 221-248.

Stevanovic, S. (2013). Optimization of passive solar design strategies: A review. Renewable and Sustainable Energy Reviews (Volume 25), 177-196.

US Department of Energy (2018), EnergyPlus ${ }^{\mathrm{TM}}$ Version 9.0.1 Documentation. 